PLURAL, Revista do Programa de Pós-Graduação em Sociologia da USP, São Paulo, v.15, 2008, pp.81-98

\title{
A perspectiva queer aplicada ao contexto brasileiro: apontamentos para uma sociologia histórica*
}

\section{Oswaldo Lara**}

Resumo: Este trabalho é o resultado parcial da pesquisa $A$ sexualização da "raça" em Bom-crioulo (1895) de Adolfo Caminha: a emergência do dispositivo de sexualidade no Brasil. A reflexão aqui empreendida se divide em três momentos principais: no primeiro, apresento os desenvolvimentos teóricos que marcam a recepção da teoria queer no âmbito desta pesquisa; num segundo momento, apresento os desdobramentos particulares que levaram à relaçáo entre sexualidade e raça no contexto brasileiro em fins do século XIX; por fim, retomo a centralidade da análise sociológica para a pesquisa sobre as trajetórias históricas que produzem categorias e identidades sociais.

Palavras-chave: sexualidade; raça; literatura; sociologia histórica.

\section{The queer perspective applied to the Brazilian context: pointing to a historical sociology}

Abstract: This work is part of the research project entitled A sexualização da "raça" em Bom-
-crioulo (1895) de Adolfo Caminha: a emergência do dispositivo de sexualidade no Brasil
and is divided in three parts. In the first, the theoretical development that fix the reception of
the queer theory in the scope of this research is presented. In the second, the particular displays
that leaded to the relation between sexuality and race in the Brazilian context at the end of the
XIX century is presented. Finally, the centrality of the sociological analyses to the development of
the research about the historical career that produces social categories and identities is resumed. Keywords: sexuality; race; literature; historical sociology.

* Recebido em 16 de agosto de 2008. Aprovado para publicação em 26 de maio de 2009.

" Oswaldo Lara é mestrando do Programa de Pós-Graduação em Sociologia da Universidade Federal de São Carlos (UFSCar). 


\section{INTRODUÇÃO'}

Ao reunir a perspectiva histórica oriunda do marxismo, as contribuiçóes do feminismo e dos estudos de gênero, a teoria queer tem proposto um novo enfoque sobre os processos sociais constituintes da modernidade. Suas proposiçóes teórico-metodológicas têm repercutido, cada vez mais, nas reflexóes sociológicas. Ao se defrontar com pesquisas sobre o contexto brasileiro, emerge a necessidade de pensarmos em intersecçóes entre "sexo", gênero e "raça". Problematizaremos essas questôes a partir de um estudo histórico sobre a sexualização da "raça" no Brasil, tomando como ponto de partida o romance Bom-crioulo (1895) de Adolfo Caminha. Primeiramente, retomamos alguns princípios presentes no conceito de gênero e, na sequência, adentramos na perspectiva queer. Por fim, discutimos como a pesquisa sobre a sexualizaçáo da raça, no romance em questáo, pode se valer dessa perspectiva, como também necessita avançar no estudo das intersecçóes entre categorias.

\section{BREVE HISTÓRICO DO CONCEITO DE GÊNERO: DAS CONSTRUÇÕES SOBRE A DIFERENÇA À DIFERENÇA CONSTRUÍDA}

Os estudos de gênero e sexualidade se inserem em debates mais amplos das ciências sociais, tais como os relativos à igualdade e diferença, à justiça e ao reconhecimento, ao essencialismo e ao construtivismo. À medida que tais estudos têm ganhado densidade teórica, ganha maior relevância a discussão sobre a intersecção das categorias de análise, anteriormente examinadas de forma paralela ou "somada". Em outras palavras, hoje busca-se abordá-las reconhecendo que podem se constituir mutuamente ao mesmo tempo que guardam uma autonomia relativa. A emergência da teoria queer na sociologia acadêmica aponta para esse espaço de problematização, em especial para as intersecçôes entre gênero, sexualidade, raça e nacionalidade.

Ainda que não possa ser reduzido a uma única perspectiva, algo que pode ser atribuído ao pensamento feminista como um todo é o questionamento do caráter natural da subordinaçáo da mulher e sua explicitação como fato socialmente construído. $\mathrm{O}$ conceito de gênero se desenvolve na busca de ferramentas conceituais mais apropriadas para desnaturalizar a opressão das mulheres ${ }^{2}$. O conceito se difunde, sobretudo, com Gayle Rubin a partir do ensaio $O$ tráfico das mulheres: notas sobre a economia política do sexo. Ao realizar uma leitura crítica de Lévi-Strauss e Freud, Rubin

\footnotetext{
${ }^{1}$ Este trabalho é o resultado parcial da pesquisa $A$ sexualização da "raça" em Bom-crioulo (1895) de Adolfo Caminha: a emergência do dispositivo de sexualidade no Brasil, financiada pela Fapesp, e parte do projeto temático de meu orientador, intitulado "Ciências, Literatura e Nação: as relaçóes entre o darwinismo-social e a emergência do dispositivo de sexualidade no Brasil 1870-1930". Ela se insere ainda nas discussóes do Grupo de Pesquisa Corpo, Identidade Social e Estética da Existência coordenado pelo Prof. Dr. Richard Miskolci.

2 Para um histórico ampliado do conceito de gênero e suas relações com a prática feminista, ver Piscitelli, 2002.
} 
[...] definiu o sistema sexo/gênero como o conjunto de arranjos através dos quais uma sociedade transforma a sexualidade biológica em produtos da atividade humana, e nas quais estas necessidades sociais transformadas são satisfeitas. (PISCITELLI, 2002, p.17.)

Na reelaboração do conceito de gênero, um dos problemas apontados por estudiosas como Dona Haraway era o perigo de tornar intactas identidades essenciais como "homem" e "mulher" decorrente de uma distinçáo binária. Para a autora, o gênero deveria estar associado a uma série de outras categorias que pudessem ser historicizadas, chegando às teorias da corporificação, retirando assim uma natureza imaginada como base neutra para a cultura. Esse deslocamento seria levado às últimas consequências por Judith Butler em uma compreensão da construção inteiramente social da diferença sexual. Trata-se de um questionamento das raízes epistemológicas da distinção sexo/gênero, na qual o próprio sexo aparece como construção cultural. Nessa formulaçáo, Butler propóe que o gênero é anterior ao sexo ${ }^{3}$.

Dessa forma, outras diferenças passaram a ser questionadas, levando a reflexôes que se deslocavam do binário homem/mulher. Consequentemente, o local de construção da subjetividade não esteve mais unicamente associado às categorias tradicionais de classe, trabalho e divisão sexual do trabalho, mas também a outras "constelações transversais" como o corpo, a sexualidade, a raça e a nacionalidade (PRECIADO, 2007, p.383).

O próprio sexo é visto não mais como dado natural, mas como categoria a ser historicizada, levando uma série de estudiosos a uma releitura de Michel Foucault, particularmente do primeiro volume de História da Sexualidade, intitulado A vontade de saber (2005).

Mais uma vez nos deparamos com o trabalho de Gayle Rubin, desta vez em Pensando sobre sexo (1984). A antropóloga feminista logrou êxito ao demonstrar, a partir do exemplo norte-americano, a consolidação de um sistema de estratificaçấo sexual na segunda metade do século XIX. A autora analisa como, em períodos nos quais há a reformulação das relaçóes de sexualidade, podemos detectar elementos que posteriormente extrapolam seus contextos de origem. De acordo com Rubin, assim como raça, gênero e classe possuem um status de construto social reconhecido pelas ciências sociais como formadores de estratificaçóes relativamente autônomas, devemos investigar a especificidade da estratificação social que tem como base a noção de sexo. Sexo aqui é tido como um "vetor de opressão" que atravessa outros modos de desigualdade social. Mais do que isso: rejeita-se qualquer compreensão que ignore as determinaçôes históricas e sociais do sexo e o tome como associal, náo histórico ou imutável. A perspectiva histórica póe em xeque o essencialismo sexual, abordando a sexualidade como um complexo institucional relativamente moderno.

3 Tal formulaçáo não passou despercebida às críticas e uma delas foi a de que a preocupação exagerada com a desessencialização desestabiliza o "conceito/categoria" mulheres, o que poderia dissolver o sujeito político do feminismo. 
Outra necessidade que se tem apontado é a criação de ferramentas conceituais para pensar a constituição mútua de certas categorias sem tentar hierarquizá-las. Para Beatriz Preciado, náo se trata simplesmente de levar em conta a especificidade racial ou étnica da opressáo como uma variável a mais, juntamente à opressão sexual ou de gênero, "mas também de analisar a constituição mútua do gênero e da raça - o que poderíamos chamar de sexualizaçáo da raça e racialização do sexo - em parte dos movimentos constitutivos da modernidade sexo/colonial" (PRECIADO, 2007, p.376). Preciado situa o desenvolvimento da teoria queer como uma volta reflexiva sobre as teorias feministas, por meio desses deslocamentos nas análises da identidade sexual e racial. A autora também aponta para a desnaturalizaçáo da diferença sexual nas formulaçóes de Butler e Eve Sedgwick como centrais para este ponto de inflexão. Uma vez expostos estes aspectos teórico-conceituais, podemos passar a uma especificaçáo da orientaçáo sociológica e histórica de uma vertente dos estudos queer.

\section{A TEORIA QUEER E AS DIFERENÇAS EM ABORDAGENS HISTÓRICAS}

Tradicionalmente, as práticas e enfoques da pesquisa sobre sexualidade se ligam a abordagens qualitativas, como, por exemplo, a pesquisa histórica e os processos interpretativos. Particularmente o termo queer tem sido empregado como um marcador da instabilidade da identidade, ao mesmo tempo em que busca dar conta de todos os outsiders do sexo e do gênero. Conforme observa Joshua Gamson: "[...] a teoria queer e os estudos queer propóem um enfoque não tanto sobre populaçóes específicas, mas sobre os processos de categorização sexual e sua desconstrução" (GAMSON, 2006, p.347). Ao priorizar os processos de constituição da sexualidade como dados supostamente verdadeiros, a pesquisa nessa abordagem analisa criticamente o biopoder, forma de regulaçáo individual e coletiva da vida reduzida a uma dimensão biológica.

$\mathrm{Na}$ base das principais formulaçóes queer situa-se a analítica do poder de Michel Foucault que, pioneiramente, descartou o binômio sexo/natureza para abordar a relação entre sexo e poder nos termos de uma formação cultural caracterizada pela preocupação em produzir discursos verdadeiros e práticas institucionais sobre a sexualidade. A análise queer é coerente com a proposta foucaultiana, sobretudo, no seguinte postulado:

Não se deve fazer divisão binária entre o que se diz e o que não se diz; é preciso tentar determinar as diferentes maneiras de náo dizer, como são distribuídos os que podem e os que não podem falar, que tipo de discurso é autorizado ou que forma de discrição é exigida a uns e outros. Não existe um só, mas muitos silêncios e são parte integrante das estratégias que apoiam e atravessam os discursos. (FOUCAULT, 2005, p.30.)

Ao analisar historicamente a regulação da sexualidade nas sociedades modernas, trata-se não somente de questionar os discursos, mas a vontade que os conduz e a intenção 
estratégica que os sustenta (FOUCAULT, 2005, p.14). Encontramos em Foucault uma abordagem sobre o nascimento, nas sociedades modernas, de uma incitaçáo política, econômica e técnica a falar do sexo. O governo da sexualidade pressupóe uma necessidade de gerir, inserir em sistemas de utilidade, regular para o bem estar de todos e fazer funcionar o sexo sob um padráo ótimo. Trata-se, em suma, do dispositivo de sexualidade, um dispositivo histórico que:

[...] demarca um conjunto decididamente heterogêneo que engloba discursos, instituiçóes, organizaçóes arquitetônicas, decisóes regulamentares, leis, medidas administrativas, enunciados científicos, proposiçóes filosóficas, morais, filantrópicas. Em suma, o dito e o não dito são os elementos do dispositivo. (FOUCAULT, 2004, p.244.)

Foucault tornou explícitos os princípios que nortearam sua análise do dispositivo de sexualidade. De modo sintético, trata-se de atentar para os seguintes aspectos: as conexôes entre poder e saber; as variaçóes que as relaçóes de poder apresentam de um contexto ao outro; os condicionamentos que conferem ao dispositivo sua eficácia tanto como estratégia global, como se apoiando em relaçóes precisas; e, por fim, a distribuiçáo dos discursos em campos táo distintos quanto a psiquiatria, a jurisprudência e a literatura (FOUCAULT, 2005, p.93-97).

Eve Sedgwick partilha da afirmação que o significado do que é tido como sexual varia de acordo com cada sociedade, incorporando outros elementos como raça e gênero. A ênfase da autora reside na afirmaçáo de que não há um significado universal que possa ser atribuído à sexualização das relaçóes sociais, uma vez que tal processo encontra-se subordinado aos significados históricos atribuídos à sexualidade. Sedgwick sugere, entấo, uma confluência metodológica entre as análises historicizantes do feminismo marxista e o método da desconstrução que ganhou força, sobretudo, no feminismo francês. Assim, seria possível unir a análise dos significados históricos da experiência social da sexualidade (por exemplo, tal como constituída pelo discurso médico) com o questionamento do papel que a experiência da sexualidade adquire na constituição da subjetividade (SEDGWICK, 1985, p.12-13). Sedgwick argumenta que se há uma "estrutura" da sexualidade, ela não pode ser considerada isolada das mudanças históricas que interagem com ela numa relação formativa e dialética:

[...] parecemos posicionados entre a alternativa de "ler" o sexo ou "ler" a história, uma escolha que parece ser entre o aspecto sincrônico e o diacrônico. Nós sabemos que é um equívoco ver deste modo, não só porque em abstrato o sincrônico e o diacrônico devem ser considerados um em relaçáo ao outro, mas porque especificamente nas disciplinas que nós estamos considerando eles estão mutuamente inscritos (SEDGWICK, 1985, p.13).

Ao enfocar sobre a construção do discurso sexual e seu respectivo processo de normalização, estudos como os de Sedgwick centram-se nas "formas como a própria distinção 
homo/hetero serviu de base para todos os aspectos da vida contemporânea" (GAMSON, 2006, p.353). Ao investigar a emergência desse binarismo na literatura inglesa, Sedgwick identificou o processo de formaçáo, nas sociedades burguesas, da homofobia ${ }^{4}$.

As consequências de tal processo estáo para além do campo literário, tendo colaborado para a legitimação de um certo status quo social e sexual. Sedgwick afirma, em seu estudo Between Men - English Literature and Male Homosocial Desire (1985), que cada sociedade define o que é sexual ou não, assim como avalia a aceitabilidade ou rejeiçáo de certas relaçôes a partir de critérios próprios à sua estrutura de poder. $\mathrm{O}$ ponto de partida da autora foram as grandes mudanças econômicas, ideológicas e na organização de gênero, que consolidaram o processo de aburguesamento da sociedade inglesa entre meados do século XVIII e meados do século XIX.

Sedgwick leva adiante o empreendimento em seu livro Epistemology of the Closet (1990), no qual argumenta que um entendimento de qualquer aspecto da moderna cultura ocidental será incompleto e prejudicado na medida em que não incorpore uma análise crítica da definição moderna de homo/heterossexual. Para Sedgwick, em sociedades marcadas pelo dispositivo de sexualidade, o "senso comum" discursivo e institucional é caracterizado por uma recusa cognitiva da homossexualidade, ou seja, formado pela ideia de uma sexualidade particular constituída como segredo. Esse contexto, no qual identidade sexual é sinônimo de identidade compulsória, é marcado por uma incoerência interna e por um conjunto de interdiçóes contraditórias, ou seja, cria uma identidade social que é ao mesmo tempo proibida e necessária para a existência da identidade hegemônica.

Segundo Sedgwick, mais do que uma discussão pró-homossexual ou anti-homossexual, o objetivo é analisar as contradiçóes mais ativas que são internas a todos os importantes movimentos que, desde o final do século XIX, definiram o binômio homo/heterossexual. Percebe-se que tal perspectiva difere dos estudos sobre a constituição de "minorias" sexuais, uma vez que se voltam para o processo de constituição "daqueles conhecimentos e daquelas práticas sociais que organizam a 'sociedade' como um todo, sexualizando - heterossexualizando ou homossexualizando - corpos, desejos, atos, identidades, relaçóes sociais, conhecimentos, cultura e instituiçóes sociais" (SEIDMAN, 1996, p.12-13).

Parte central da análise de Sedgwick apoiou-se na investigação de obras literárias para compreender como emergiu a ordem social do presente. Em se tratando de uma obra literária, esse tipo de análise busca explicitar que a matéria do artista é historicamente informada e registra, de algum modo, o processo social a que deve sua existência. No caso da análise da sexualidade, a ênfase reside nos processos sociais de sexualização. De

\footnotetext{
${ }^{4}$ Sedgwick usava a expressão "homofobia" em sua teorização. Entretanto, na atualidade, Miskolci propóe que priorizemos o termo "heterossexismo" para falar das pressóes sociais em prol da heterossexualidade, e homofobia apenas para se referir a subjetividades moldadas pela heteronormatividade e, portanto, marcadas pelo medo de se denunciar ao revelar publicamente o desejo homoerótico. Em sua análise, heterossexismo institucional (heteronormatividade) e homofobia espelham um ao outro, mas o termo homofobia, como sinônimo de violência ou perseguiçáo ao desejo homoerótico, é impreciso e altamente discutível. Agradeço a Richard Miskolci por essa observação feita em comunicação pessoal.
} 
acordo com Sedgwick, tais processos se tornaram produtores da cultura e da história das sociedades modernas, prescrevendo necessidades representacionais, tanto para classificaçáo dos sujeitos "aceitáveis" como para os "desviantes".

Náo se trata de assimilar mecanicamente a obra literária ao seu contexto, mas sim de analisar como a literatura retrata (e é parte de) certas experiências históricas (MISKOLCI, 2007, p.2), nos fornecendo um arquivo privilegiado para estudos sociológicos e históricos. Após termos explicitado nossos princípios teóricos, passando pela abordagem histórica, pelo feminismo até chegarmos à hipótese foucaultiana, passamos à apresentação de algumas reflexóes iniciais de uma pesquisa sobre a sexualização da raça no Brasil, processo que emerge no final do século XIX e tem como contexto a recepção nacional das teorias sobre degeneraçáo social. A afinidade com o enfoque acima sumarizado deve-se não somente ao paralelo histórico e temático, mas também por se tratar de um estudo que tem como ponto de partida uma obra literária, o romance Bom-crioulo de Adolfo Caminha.

\section{A PERSPECTIVA QUEER APLICADA AO CONTEXTO BRASILEIRO}

Faz cem anos que Bom-crioulo explodiu no seio da Marinha brasileira, causando danos incalculáveis à sua imagem. O livro de Adolfo Caminha, escritor cearense, ex-oficial da Marinha, narrava de forma detalhada o romance entre o marinheiro negro Amaro e o grumete louro Aleixo. Paixáo sensual, que se desenvolveu nos conveses, poróes e cantos mais protegidos de uma corveta da esquadra brasileira e que se concretizou em ligação assumida num quartinho alugado no centro do velho Rio. Durante um ano viveram em paz e harmonia. Mas um dia Aleixo se cansou dos apelos do Bom-crioulo (audaciosamente descritos por Caminha) e resolveu experimentar emoção nova e mais próxima das formas ortodoxas do amor nos braços da quarentona portuguesa que alugara o quarto aos dois amantes. As desconfianças de Amaro [...] acabam por provocar o desenlace trágico, com Aleixo sendo assassinado pelo Bom-crioulo. A história do homossexualismo, a descrição detalhada da paixão homossexual por si só, devia causar espécie naquele final de século brasileiro. (O GLOBO, 29 dez. 1995.)

O romance Bom-crioulo narra uma história que se passa quase que exclusivamente no universo masculino. Ao longo de suas pouco mais de cem páginas, acompanhamos a aparição, com maior ou menor relevância, de marinheiros, tenentes, comandantes, homens de ganho, açougueiros, caixeiros, catraieiros, médicos, enfermeiros, engenheiros, padeiros e guardas municipais. A única personagem mulher de importância para o enredo é a prostituta Carolina. Fora ela, alguns vagos registros de prostitutas de outras nacionalidades, a máe Sabina, que o Bom-crioulo deixara na fazenda, e as senhoras que apareciam na janela para assistir a algum "rolo" que acontecesse nas ruas. A narrativa se inicia em alto mar num navio de guerra, contando-nos o caso de amor à primeira vista de Amaro em relação a Aleixo. Instalados na capital do então Império do Brasil, o casal 
passa a viver numa pensão e envolve-se, mais tarde, num conturbado triângulo amoroso que leva ao desfecho trágico do romance.

Como um romance pode ser lido por seus contemporâneos? Como um romance que se volta basicamente para o universo das alteridades, supostamente indesejadas em relaçáo à cultura dominante, pode ser entendido? Em que pese vários debates acerca de suas diversas influências artísticas ${ }^{5}$, o próprio Caminha afirmou seu conhecimento das teorias médico-científicas de sua época ${ }^{6}$. Ao naturalizar comportamentos e identidades, tais teorias ofereciam um esquema de percepção para os temores sociais mais candentes daquele período. Até nossos dias, o esforço de historicização esbarra em tais percepçóes naturalizadas e a investigação sociológica aponta para a necessidade de aprofundarmos o debate.

Os líderes militares haviam estabelecido um governo republicano há somente seis anos e a escravidão havia sido abolida há apenas sete, quando Bom-crioulo, de Adolfo Caminha, surge no cenário das letras em novembro de 1895. Em outras palavras, esse romance, que narra a relação amorosa entre dois homens, foi publicado num momento de importantes transformaçóes na sociedade brasileira: trata-se de um processo de complexificação de nossa estrutura social, em que a transição para uma sociedade livre e republicana não eliminou as contradiçôes de uma ordem social racista e moralmente conservadora. As identidades sociais representadas em Bom-crioulo, sobretudo a do protagonista Amaro, negro e homossexual, estavam sendo criadas (em seu sentido moderno) justamente nesse contexto de invenção do cidadão nacional, ou seja, num jogo de interrelação com um modelo de identidade hegemônica. O pensamento social brasileiro de fins do século XIX respondeu a este contexto com um diagnóstico que expressava o temor de degeneração. A hipótese aqui trabalhada é a de que um romance como Bom-crioulo não representa apenas uma forma de classificação de certas identidades e tipos sociais, mas também, e sobretudo, a emergência do dispositivo de sexualidade no contexto brasileiro ${ }^{7}$.

A chegada das teorias sobre a degeneração em solo brasileiro coincidiu com o período final do Império (1880-1889) e sua retórica foi empregada tanto por críticos sociais reformistas, como por elaboradores da ideologia oficial ao longo da Primeira República. Os porta-vozes dessas ideias tinham como referência as teorias científicas que se fundamentavam na biologia desde a publicação por Charles Darwin de $A$ origem das espécies (1859), que trouxeram consigo um padrão epistemológico que se tornou fonte explicativa até mesmo para as ciências humanas, desembocando na corrente conhecida como darwinismo social (MISKOLCI, 2005, p.16). Dain Borges aponta para a inexistência

\footnotetext{
5 Ver, por exemplo, Howes, 2005.

${ }^{6}$ Cf. Green, 1999 e Howes, 2005.

7 Esta é hipótese da pesquisa $A$ sexualização da "raça" em Bom-crioulo (1895) de Adolfo Caminha: a emergência do dispositivo de sexualidade no Brasil que também faz parte de um projeto temático mais amplo coordenado pelo Prof. Dr. Richard Miskolci, intitulado: Ciências, literatura e nação: o darwinismo-social e a emergência do dispositivo de sexualidade no Brasil (1870-1930).
} 
de um campo intelectual autônomo como fator que favorecia esta permeabilidade das ideias científicas em relação à literatura:

Ideias sociais de degeneração e temas psiquiátricos de caráter provavelmente encontraram sua aplicação mais ampla năo diretamente na escrita médica, mas indiretamente através da literatura naturalista. O subdesenvolvido campo intelectual brasileiro tinha uma frágil profissionalização e compartimentação. A educação médica era tanto literária e retórica quanto prática e a escrita médica frequentemente emprestava imagens da literatura romântica e naturalista, assim como estas tomavam emprestado imagens da medicina. (BORGES, 2005, p.49).

Frequentemente associada a desviantes sexuais, prostitutas e criminosos, aqui a degeneraçáo agregou também as preocupaçôes com a população negra, o consequente temor da miscigenação e as políticas de "embranquecimento" da populaçáo (ibidem, p.65). Nesse sentido, a proposta de um romance que fosse um "estudo de comportamento" baseado na "observação da realidade", apresentava mais que descriçóes neutras. Ele procurava compreender questóes sociais como o crescimento da populaçáo urbana, $\mathrm{o}$ declínio da escravidão e a constituição de novos sujeitos. Tratava-se também da invenção de alteridades que tiveram o papel de antinorma de uma sociedade que iniciava seu processo de aburguesamento ${ }^{8}$. A literatura desse período, mesmo que num estreito diálogo com a ciência determinista, expunha maiores tensóes ao dar relevo às identidades que no discurso científico permaneciam como categorias apriorísticas.

Segundo o historiador James Green, "[...] a patologização da homossexualidade no Brasil, iniciada no fim do século XIX, caminha em paralelo com o processo na Europa descrito por Foucault em História da sexualidade I - A vontade de saber" (GREEN, 1999, p.114). O tema da homossexualidade foi o principal alvo dos detratores de Bom-crioulo, suscitando uma reação pública de Caminha que, nas palavras de Green:

[...] indica uma familiaridade com a literatura europeia sobre o erotismo entre pessoas do mesmo sexo. De fato, o uso da palavra homossexualismo em sua defesa de Bom-Crioulo, em 1896, era uma das primeiras aplicaçóes literárias, no Brasil, do termo que fora cunhado em 1869 pelo escritor vienense Karoly Maria Benker?. (GREEN, 1999, p.77.)

\footnotetext{
${ }^{8}$ Na pesquisa de Beluche, percebemos o debate entre historiadores sociais como Sidney Chalhoub, que consideraram mecânica a assimilaçáo da tese foucaultiana sobre o aburguesamento brasileiro nos trabalhos iniciais de Joel Birman e Jurandir Freire Costa. Este, por sua vez, reconhece que seu objetivo central foi mais a constituiçáo do "imaginário cultural" que a fidelidade histórica (cf. REVISTA DE HISTÓRIA DA BIBLIOTECA NACIONAL, 2009). Atento a esses debates, o próprio trabalho de Beluche deu prosseguimento à investigação da tese foucaultiana, mas observando a crítica da historiografia social (cf. BELUCHE, 2006).

9 O nome que consta na tradução do livro de Green provavelmente refere-se ao panfleto do ativista húngaro Karl Maria Kertbeny contra a criminalização das relaçóes entre homens (cf. HALPERIN, 2000; MISKOLCI, 2006a).
} 
As motivaçôes de fundo moral por parte da crítica literária se baseavam numa série de discursos religiosos, jurídicos e médicos que criaram a representação do homossexual como um ser degenerado. O que podemos perceber, é que a homossexualidade masculina no Rio de Janeiro tornou-se tema de preocupação médica e psiquiátrica, bem como o controle das açôes destes que eram tidos como "homens transgressivos". Um dos críticos, Valentim Magalhães, membro fundador da Academia Brasileira de Letras, escreveu no jornal $A$ Notícia sua condenação à obra e seu autor:

Este moço é um inconsciente, por obcecação literária ou perversão moral. Só assim se pode explicar o fato de haver ele achado literário tal assunto, de ter julgado que a história dos vícios bestiais de um marinheiro negro e boçal podia ser literariamente interessante. (HOWES, 2005, p.174.)

A referência à degeneração e à forma como a ideia de sexualidade transgressiva estava associada a esta última tornou-se uma das questôes obrigatórias para os cientistas e literatos contemporâneos de Caminha:

Em 1885, um médico, Ferreira Leal, publicou a novela Um homem gasto, retratando um homossexual de classe média alta que casa-se (sic) mas só é capaz de ato matrimonial com a ajuda de drogas e suicida-se quando não pode mais suportar. O Ateneu, de Raul Pompeia (1888) refere-se a uma apaixonada relação entre rapazes num internato, enquanto Aluísio Azevedo incluiu três estereótipos homossexuais clássicos, um jovem efeminado, um velho sujo e uma prostituta lésbica agressiva, em seu romance naturalista $O$ cortiço, de 1890. ( HOWES, 2005, p.176.)

No Brasil, levando em conta o passado escravista, vemos intensificar-se ainda mais o temor da sexualidade interracial e, principalmente, de seu resultado possível, o declínio da população. O principal mecanismo de classificação do negro como o "Outro" foi a sexualidade que, "estruturada em um discurso biologizante, permitiu discutir questôes sociais como se fossem problemas de natureza científica e, portanto, pretensamente neutros" (BELUCHE, 2006, p.95).

Para muitos, a degeneração parecia ter adquirido um potencial endêmico e, no caso brasileiro, as ansiedades e temores geraram pânicos morais em diversos romances (naturalistas ou não). As consequências da miscigenação foram retratadas em diversas obras de Aluísio Azevedo, a problematização da sexualidade adolescente ganhou foco em O Ateneu (1888), os pânicos sexuais advindos da recente abolição da escravidão se mesclaram à patologização e criminalização das relaçóes entre homens em Bom-crioulo (1895), até que a naçáo compreendida em termos do Darwinismo social se torna protagonista romanesca em Os sertóes (1903) de Euclides da Cunha.

Das obras literárias citadas anteriormente, devemos notar a diferença de abordagem das relaçóes entre Amaro e Aleixo quando comparadas a um romance como O Ateneu, 
que apresenta uma leitura da sexualidade das classes dirigentes. Analisando a aceitabilidade e a rejeição de certas relaçóes, Richard Miskolci observa os diferentes mecanismos de normalização dirigidos de acordo com as diferentes posiçôes de classe social:

No Brasil, quase ao mesmo tempo em que as relaçóes entre rapazes aparecem nas classes altas como uma fase em direção à vida adulta (associada com a heterossexualidade), um outro modelo de compreensão serviu para Adolfo Caminha em seu polêmico Bom-crioulo (1895), romance em que a relação entre um marinheiro negro e um branco é apresentada segundo as recentes teorias que viam nela a expressão de uma mente doentia e criminosa. Portanto, se entre os burgueses a homossexualidade não era aceitável, mas era vista como uma fase, entre as classes populares ela era vista como a prova da degeneração racial. (MISKOLCI, 2006a, p.13.)

Se a categoria "negro" era indicativa de uma propensão ao crime, sua intersecção com o status conferido à homossexualidade funcionava como marcadora de doença, perigo, perversão, crime e amoralidade. Temas como homossexualidade e raça foram fundamentais para a invenção dos "anormais" na sociedade brasileira no final do século XIX ${ }^{10}$. Eles serviram de referência para a produção de identidades sexuais, bem como para a consolidação de nossas hierarquias raciais. Adolfo Caminha esteve enredado nas teorias raciais do fim do século XIX e o modo como se refere ao negro apresenta o vocabulário do racismo científico do fim do século XIX. Como bem observa Flora Sussekind:

Com relação a Amaro, destacam-se como traços marcantes a "musculatura rija", os "arrebatamentos", a "tendência para o crime". Noutras palavras, a força física e a potencialidade do negro para trabalhos braçais; um erotismo doentio e descontrolado; uma criminalidade latente. Amaro se aproxima assim das teorias raciais em voga na sociedade brasileira da virada do século. A ele, como se atribuía ao negro enquanto raça, se dá um destino marcado pelo trabalho, por uma supererotização, pela criminalidade (SÜSSEKIND, 1984, p.138.)

Se concordarmos com a proposição de Avtar Brah de que em sociedades pós-coloniais como a nossa há um processo de "racialização do sexo" e "sexualização da raça", é possível apontar para algumas das especificidades colocadas pela problemática racial aos elementos históricos do dispositivo de sexualidade. No Brasil, a história desse dispositivo foi fortemente marcada pela problemática da cor, como demonstram as inúmeras discussóes sobre o caráter da miscigenação. As quatro estratégias que, como veremos, caracterizaram a sexualidade no século XIX, foram atravessadas pela questáo da "população negra". A histerização do corpo feminino e suas correlaçôes foram marcadas pela diferenciação entre

\footnotetext{
${ }^{10}$ Para uma apresentaçáo do sistema de classificação das novas identidades no Brasil em finais do XIX, ver Fry, 1982, pp.33-51.
} 
mulheres brancas, negras e mestiças. No caso da socialização das condutas procriativas, a preocupação com o status do casal miscigenador e as políticas de "embranquecimento" da populaçáo foram centrais. A pedagogização do sexo não se deu sem uma devida separação dos corpos. Por fim, a psiquiatrização do "prazer perverso" (de conotaçáo racista por si mesma, pois considera a existência de um tipo humano homossexual), quando associada ao negro, assumia a conotaçáo de um atavismo característico de uma sexualidade desenfreada.

As noçôes de sexualização e racialização póem em xeque as explicaçôes que tendem a naturalizar o mundo social. Elas são utilizadas para mostrar que o que existe são relaçôes sociais, mas essas relaçôes sociais são perpassadas por clivagens como "sexo" e "raça". Tais clivagens passam a operar no interior do mundo social, fundamentando tanto os conhecimentos como as práticas sociais pensados, a partir de então, como relaçóes entre raças e relaçôes entre portadores de sexualidades distintas. Nessa perspectiva, as categorias "raça" e "sexo" interferem na organização do mundo social, relacionando-se com outras formas de desigualdade.

É recente a problematização na academia brasileira da centralidade conferida à sexualidade no discurso dos intelectuais que se debruçaram sobre nossas origens, voltados para a interpretação científica da nossa realidade e para a definiçáo da identidade nacional. Em um artigo intitulado Sexualidade e identidade na historiografia brasileira, Margareth Rago destaca "[...] a importância que o discurso da sexualidade assume na leitura que fazemos de nossas origens históricas" (RAGO, 1998, p.179).

Não havia até então um questionamento de como o desejo sexual era um pressuposto da subjetividade do cidadâo nacional. Dessa forma, é também recente a desconstrução de representaçôes misóginas, racistas e heterossexistas veiculadas por discursos hegemônicos. E, somente a partir deste ponto, tornou-se possível interrogar sobre o porquê da associação de nossa cultura sexual com a ideia de declínio da sociedade. A resposta, segundo Rago, aponta mais uma vez para a especificidade do dispositivo de sexualidade no Brasil: "Medo da degeneração da raça, do escurecimento em vez do embranquecimento populacional que tanto queriam, medo do predomínio do instinto sobre a razão, medo de uma 'psiché racial' que nos predeterminaria ao fracasso" (RAGO, 1998, p.182).

"Sexo" e "raça" foram tomados como termos privilegiados que, com base no argumento da "natureza brasileira", serviram de explicação para os comportamentos tidos como transgressivos para a sociedade do final do século XIX. Expondo nossas contradiçôes e de nossa intelectualidade, as ideias de "raça superior" e "raça inferior" associadas ao imaginário de anormalidade então emergente sobre as sexualidades desviantes, a identidade de negros e mestiços se tornou central naquele contexto: "[...] o mestiço é capitoso, sensual, irrequieto, fermento de dissolução que justifica todas as transgressóes e constitui em face do europeu um perigo e uma tentação" (CANDIDO, 2004, p.118). Percebemos assim, como a mútua implicação de sexualidade e raça engendrou identidades produzidas em relaçóes que visavam a manutenção de hierarquias num contexto de transformaçôes sociais. Os discursos de literatos e cientistas da época problematizavam, 
de acordo com o novo vocabulário da sexualidade, relaçóes que se tornaram mais visíveis e alvo de preocupação. Embora suas estratégias e posicionamentos não fossem idênticos, ambos se referiam ao contexto médico, legal e psiquiátrico.

Analogias usadas pelos cientistas no sentido de afirmar a inferioridade nata de certos indivíduos e grupos sociais fundamentavam-se em metáforas preestabelecidas, familiares e culturalmente arraigadas (STEPAN, 1994, p.76). Tais metáforas foram incorporadas também pela literatura e sua eficácia explicativa era maior na medida em que se adequassem às expectativas sociais. A suposta inferioridade de certas categorias raciais e sexuais naturalizou-se a tal ponto que seu caráter metafórico terminou dissimulado. As observaçôes de Nancy Stepan a esse respeito sáo elucidativas:

Quando, no século XIX, os cientistas postularam uma analogia entre diferenças raciais e sexuais, ou entre diferenças de raça e classe, e começaram a produzir novas informaçóes com base em tais analogias, suas interpretaçōes das diferenças e similaridades humanas foram amplamente aceitas, e uma das razóes para esta aceitação eram suas congruências fundamentais com a expectativa cultural futura. (STEPAN, 1994, p.77.)

À incorporação de hierarquias pré-estabelecidas, somou-se a emergência da moderna definição de sexualidade. Tal processo impôs a demarcaçáo de posiçóes que indicam o momento de formaçáo da heteronormatividade. O Bom-crioulo foi lançado no ano de 1895, num momento significativo para a história da sexualidade. No mesmo ano, o escritor inglês Oscar Wilde era condenado a dois anos de trabalho forçado após um processo em que era acusado de homossexualidade (Cf. MISKOLCI, 2006b). Anos antes, em 1870, o neurologista alemão Karl Westphal publicava o texto As sensaçôes sexuais contrárias, no qual definia o homossexual como alguém que sofreria de uma inversão do masculino e do feminino: "Dessa forma, o homossexual passou a ser visto como uma verdadeira "espécie" desviada e passível, portanto, de controle médico-legal” (MISKOLCI, 2007, p.104).

No romance de Caminha, a homossexualidade é expressa por meio de uma gramática de perífrases e preteriçóes que, de acordo com Leonardo Mendes, se confirma no emprego de termos do tipo "aquilo", "cousas", "cousas medonhas" que delimitam o domínio das "perversôes" (MENDES, 2004, pp.61-62). Colocado em evidência entre bondade e maldade, ou seja, entre subserviência e transgressão, o "terrível Bom-crioulo" (CAMINHA, 1997, p.33) é constantemente avaliado pelos critérios de normal ("manso", "resignado", "forte", "meigo") e patológico ("fera desencadeada", "homem perigoso", "ladrão"). Quando se vê acometido pelo "desejo fisiológico [...] que em todas as espécies impulsiona o macho para a fêmea" (CAMINHA, 1997, p.43), Amaro mostra-se confuso na tentativa de compreender a si próprio:

E agora, como é que não tinha forças para resistir aos impulsos do sangue? Como é que se compreenderia o amor, o desejo da posse animal entre duas pessoas do mesmo sexo, entre dois homens? [...] 
É certo que ele náo seria o primeiro [...]. Mas - instinto ou falta de hábito - alguma cousa dentro de si revoltava-se contra semelhante imoralidade que outros de caráter superior praticavam quase todas as noites ali mesmo sobre o convés... (CAMINHA, 1997, pp.48- 49).

O Bom-crioulo não deixa de pensar em sua "amizade inexplicável" com o grumete e, antes de desembarcarem no Rio de Janeiro, realiza seu "apetite selvagem" pelo jovem. Quando chega à cidade, planeja viver junto com Aleixo num quarto alugado à rua da Misericórdia. Decidido a levar a diante sua relação com o grumete, encontra uma justificativa baseada na inferioridade racial para seu desejo:

Nunca se apercebera de semelhante anomalia, nunca em sua vida tivera a lembrança de perscrutar suas tendências em matéria de sexualidade. As mulheres o desarmavam para os combates do amor, é certo, mas também não concebia, por forma alguma, esse comércio grosseiro entre indivíduos do mesmo sexo. [...] De qualquer modo estava justificado perante sua consciência, tanto mais quanto havia exemplos ali mesmo a bordo, para não falar em certo oficial de quem se diziam cousas medonhas no tocante à vida particular. Se os brancos faziam, quanto mais os negros! (CAMINHA, 1997, p.61; grifos meus.)

Gradativamente, o Bom-crioulo vai sendo caracterizado pela perda de racionalidade e da objetividade. Nesse sentido, a literatura fez parte desta injunçáo histórica formadora da moderna definição de sexualidade, especialmente na fabricação imaginária do homossexual moderno, que elegeu o "exotismo" como um de seus elementos-chave (MENDES, 2004, p.65).

Estudos como o realizado por Jurandir Freire Costa em $A$ inocência e o vício apontam para a importância que a invenção do estereótipo "homossexual" teve, funcionando como antinorma do ideal de conduta sexual masculina adequado à formação da família burguesa. Indissociável do contexto médico-legal e psiquiátrico no qual surgiu, a identidade social do "anormal" ocupou na dimensão da subjetividade "a posiçáo de objeto do desejo de destruição da maioria que em nome da norma ideal outorga-se o poder de atacar ou destruir física ou moralmente os que dela divergem ou simplesmente se diferenciam (COSTA, 2002, p.19). Quando analisada em termos históricos, percebemos que a noção de identidade fundada na atração física pelo mesmo sexo biológico é que possibilita a busca do "verdadeiro homossexual" (COSTA, 2002, pp.30-31). Ainda que pareça simples, tal constataçáo demonstra que o "verdadeiro homossexual" é um efeito histórico do processo de sexualização. Nesse sentido, vale observar que, historicamente, tanto homossexualidade quanto heterossexualidade são herdeiras do mesmo contexto discriminatório. Assim, Costa recorre também à literatura moderna para acompanhar as transformaçóes históricas na definiçáo da sexualidade.

De um modo instigante, Costa iniciava sua argumentação trazendo um trecho de uma autobiografia de 1837 extraído de uma pesquisa do historiador Peter Gay: nele, o 
jovem Albert Dodd declarava em cartas seu amor tanto por moças quanto por rapazes. Intencionalmente, o ponto de partida escolhido por Costa procurava evidenciar a arbitrariedade da divisão homo/hetero que se cristalizaria na literatura dos anos seguintes. Ainda que tenham tentado resignificar, ou mesmo subverter, a associação direta com a noção de degenerescência, os escritores em questão se referiam a uma visão sustentada pelo binário homo/hetero. Assim, em Proust, os "descendentes da raça de Sodoma" eram caracterizados por sua refinada sensibilidade. No internato de Raul Pompeia, a homossexualidade aparecia como estágio do desenvolvimento psíquico e moral do indivíduo. Por fim, em Adolfo Caminha, o homossexual apareceria relacionado à criminalidade (COSTA, 2002, pp.46-51).

\section{A INTERSECÇÃO ENTRE CATEGORIAS DE DIFERENÇA}

Coerente com o objetivo de analisar essa experiência histórica, o exemplo brasileiro aqui trabalhado permite compreender em partes como se engendraram novas identidades sociais a partir de processos sociais que geraram critérios próprios de classificaçáo, hierarquização e controle social dos "degenerados". Mais do que conceitos ou descriçóes da realidade, os discursos e práticas enfocados nos levam a uma compreensão dos mecanismos de resistência a mudanças na estrutura de poder da sociedade brasileira no final do século XIX. Uma obra como Bom-crioulo fornece um meio útil para reconstituir a formaçáo desses novos sujeitos do desejo divididos entre aceitáveis e desviados.

A pesquisa histórica sobre as mudanças que marcaram nossa formação social, e as identidades nela produzidas - guarda contribuiçóes a serem exploradas nos debates sobre diferença e na crítica ao essencialismo. Nesse caso particular, por exemplo, compreendemos melhor as normas de produção dos conhecimentos que tornaram certas experiências históricas possíveis. Em outras palavras, ela nos traz o entendimento de como certos grupos experimentaram a sexualização e a racialização de suas posiçôes sociais. Trata-se aqui da referência aos processos históricos que, através do discurso, posicionam sujeitos e apresentam suas experiências, conforme bem aponta Joan Scott:

Não são indivíduos que têm experiência, mas sim os sujeitos que são construídos pela experiência. Experiência nessa definição torna-se, então, não a origem de nossa explanação, não a evidência legitimadora (porque vista ou sentida) que fundamenta o que é conhecido, mas sim o que procuramos explicar, sobre o que o conhecimento é apresentado. Pensar sobre a experiência desse modo é historicizá-la, bem como historicizar as identidades que ela produz. (SCOTT, 1998, p.304).

O essencialismo, ou seja, "a noção de essência última que transcenderia limites históricos e culturais" (BRAH, 2006, p.331), pode assim, não somente ser criticado, mas também datado e analisado. A socióloga Avtar Brah problematiza a diferença como 
categoria analítica, demonstrando como esta última articula a experiência, as relaçóes sociais, a subjetividade e a identidade. Para Brah, deve-se colocar em questáo qual é o princípio organizador das categorias em cada contexto, isto é, quando está operando a sexualização, a racialização ou mesmo a contestação de seus significados. Um dos procedimentos enfatizado por Brah é justamente a pesquisa sobre as trajetórias históricas das circunstâncias, tanto micro quanto macro, que produzem identidades de grupo. Para a autora, "não se trata de compartimentalizar opressóes, mas chegar a um entendimento de como se interconectam e articulam" (ibidem, p.376).

Particularmente, na pesquisa sobre Bom-crioulo, muitas dessas intersecçóes estão por ser exploradas, uma vez que há uma quantidade considerável de fontes a serem consultadas. Mesmo nos documentos envolvendo os conflitos com a crítica literária, não se trata de buscar quais eram as vontades individuais do artista, antes como se constituíram e organizaram relaçóes sistemáticas em torno de uma problemática comum ${ }^{11}$.

Buscou-se, na reflexão empreendida, confrontar questóes teórico-metodológicas com os desafios colocados por uma pesquisa originada dos estudos queer. Partimos de um breve histórico do conceito de gênero para demonstrar como seu "impulso desnaturalizante" foi condição para sua própria crítica, da qual emerge a perspectiva queer. O objetivo foi demonstrar como tais correntes de estudos têm ganhado densidade teórica e não estabelecer uma sucessão entre elas. Adentramos em algumas das propostas centrais da análise queer, especialmente em sua vertente ligada aos estudos culturais. Por fim, apresentamos um dos desdobramentos de tal perspectiva para a pesquisa sobre a emergência do dispositivo de sexualidade no contexto brasileiro, voltando à discussáo metodológica para as interconexôes entre categorias como raça e sexualidade. Trata-se de um debate aberto a novas contribuiçóes que, como pudemos perceber, não se encerram em uma única fronteira disciplinar, mas antes incorporam abordagens de diversos temas da sociologia, da teoria feminista, da história e da filosofia desde uma perspectiva náo heteronormativa.

\section{REFERÊNCIAS BIBLIOGRÁFICAS}

BELUCHE, Renato. O corte da sexualidade: o ponto de viragem da psiquiatria brasileira no século XIX. Dissertaçáo (mestrado em Ciências Sociais). São Carlos: PPGCS, 2006.

BORGES, Dain. “'Inchado, feio, preguiçoso e inerte': a degeneração no pensamento social brasileiro, 1880-1940”. Tradução de Richard Miskolci. Teoria \& Pesquisa. São Carlos: 2005, pp.43-70. (Dossiê normalidade, desvio, diferenças.)

\footnotetext{
${ }^{11}$ Nesse sentido, a proposta de Pierre Bourdieu é importante, mas deve ser incorporada com reservas. Se por um lado, são fundamentais a desconstrução da ideia de gênio criador e a definição de uma problemática comum, por outro, seu recorte sobre a gênese e estrutura do campo literário demonstra eficácia somente para análise daquelas obras que tinham como problemática a própria criação do campo literário.
} 
BRAH, Avtar. "Diferença, Diversidade, Diferenciação". Cadernos Pagu, Campinas, n. 26, 2006, pp.329-376.

CAMINHA, Adolfo. Bom-crioulo. Rio de Janeiro: Artium, 1997.

COSTA, Jurandir Freire. A inocência e o vício - estudos sobre o homoerotismo. Rio de Janeiro: Relume Dumará, 2002.

FOUCAULT, Michel. A vontade de saber - história da sexualidade 1. São Paulo: Graal, 2005. Microfísica do poder. Rio de Janeiro: Graal, 2004

GAMSON, Joshua. "As sexualidades, a teoria queer e a pesquisa qualitativa". In: DENZIN, N.K.; LINCOLN, Y. S. O planejamento da pesquisa qualitativa. Porto Alegre: Artmed: Bookman, 2006, pp.345-362.

GREEN, James. Além do Carnaval. São Paulo: Unesp, 1999.

HALPERIN, David. M. "How to do the History of Homosexuality". GLQ: A Journal of Lesbian and Gay Studies, 2000, pp.87-124.

HOWES, Robert. "Raça e sexualidade transgressiva em Bom-crioulo de Adolfo Caminha". Graphos. João Pessoa, vol. 7, n. 2/1, 2005, pp.171-190.

MENDES, Leonardo. "As ruínas da homossexualidade: o gótico em Bom-crioulo, de Adolfo Caminha”. Luzo Brazilian Review, n. 41, 2004, pp.56-70.

MISKOLCI, Richard. "Do desvio às diferenças". Teoria \& Pesquisa. São Carlos, 2005. pp.9-42.

. "O vértice do triângulo: relações de gênero e sexualidade em Dom Casmurro". VIII Congresso Bianual da Brazilian Studies Association (BRASA), Nashville, 2006a. "A vida como obra de arte: Foucault, Wilde e a estética da existência". In: SCAVONE et al. (orgs.). O legado de Foucault. São Paulo: Unesp, $2006 \mathrm{~b}$.

"Comentário sobre A epistemologia do armário". Cadernos Pagu, Campinas, v. 28, 2007.

PISCITELLI, Adriana. "Re-criando a (categoria) mulher?" In: Algranti (org.). A Prática feminista e o conceito de gênero. Textos Didáticos. São Paulo, IFCH/Unicamp, 2002.

PRECIADO, Beatriz. "Entrevista a Jesús Carrillo". Cadernos Pagu, Campinas, vol. 28, 2007, pp.375-405.

RAGO, Margareth. "Sexualidade e identidade na historiografia brasileira". In: LOYOLA, Maria Andréa (org.). A sexualidade nas ciências humanas. Rio de Janeiro: UERJ, 1998.

REVISTA DE HISTÓRIA DA BIBLIOTECA NACIONAL. "O corpo é o maestro Entrevista com Jurandir Freire Costa. Revista de história da Biblioteca Nacional, Rio de Janeiro, janeiro de 2009, pp.38-43.

RUBIN, Gayle. "Pensando sobre sexo: notas para uma teoria radical da política da sexualidade". Cadernos Pagu, Campinas, vol. 21, 2003.

SCOTT, Joan Wallach. "A invisibilidade da experiência” In: Projeto História. Sáo Paulo, 1998, pp.297-325.

SEDGWICK, Eve Kosofsky. Between Men - English Literature and Male Homosocial Desire. Nova York: Columbia University Press, 1985.

SEIDMAN, Steven. Queer Theory/Sociology. Cambridge (MA): Blackwell, 1996. 
STEPAN, Nancy Leys. "Raça e gênero: o papel da analogia na ciência". In: HOLLANDA, Heloísa Buarque de (org.). Tendências e impasses: o feminismo como crítica da cultura. Rio de Janeiro: Rocco, 1994.

SÜSSEKIND, Flora. Tal Brasil, qual romance? Uma ideologia estética e uma história: o naturalismo. Rio de Janeiro: Achiamé, 1984. 